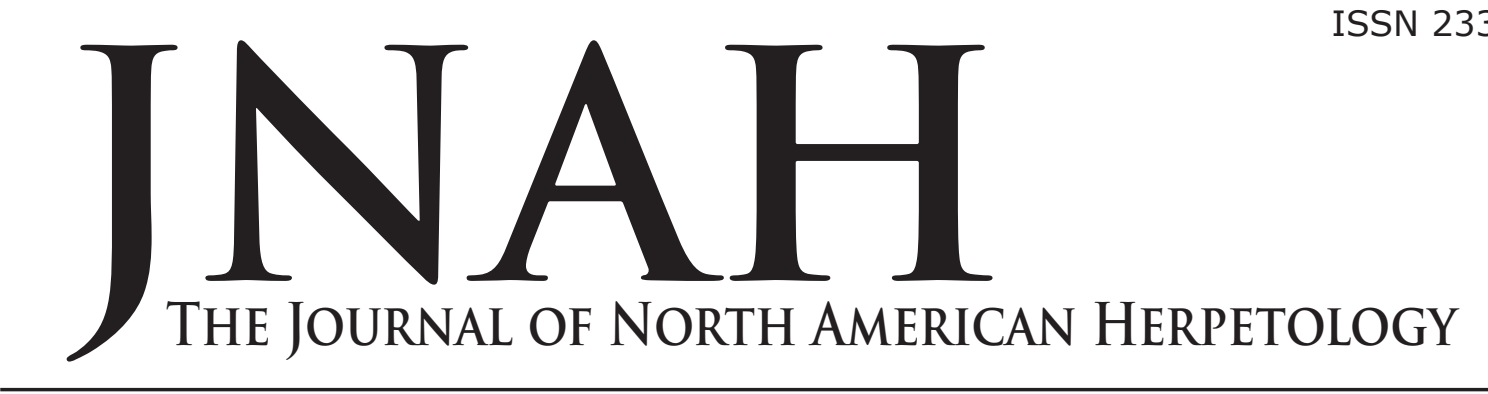

Volume 2014(1): 98-104

2 July 2014

jnah.cnah.org

\title{
INITIAL CHARACTERIZATION OF MAJOR HISTOCOMPATIBILITY COMPLEX (MHC) CLASS IIB EXON 2 IN AN ENDANGERED RATTLESNAKE, THE EASTERN MASSASAUGA (SISTRURUS CATENATUS)
}

\author{
COLLIN P. JAEGER*, RICHARD B. KING, MELVIN R. DUVALL \\ Department of Biological Sciences, Northern Illinois University, DeKalb, Illinois 60115 \\ *Corresponding author: cjaeger@niu.edu
}

\begin{abstract}
Genes of the major histocompatibility complex (MHC) play an important role in the vertebrate immune system and exhibit remarkably high levels of polymorphism, maintained by strong balancing selection. While the conservation implications of MHC variation have been explored in a variety of vertebrates, non-avian reptiles (most notably snakes) have received less attention. To address this gap and take the first steps toward more extensive population-level analyses, we cloned and sequenced MHC IIB exon 2 in an endangered rattlesnake, the Eastern Massasauga (Sistrurus catenatus). Based on three individuals, we found evidence of at least four putatively functional loci. These sequences exhibited relatively high levels of variation and significantly higher rates of nonsynonymous to synonymous substitutions, especially within the antigen-binding sites, indicating strong positive selection. Phylogenetic analysis revealed a pattern of trans-species polymorphism, also suggesting positive selection. These results contribute to our understanding of MHC variation in non-avian reptiles and form a basis for more studies of MHC variation in snakes of conservation concern.
\end{abstract}

Key Words: adaptive genetic variation; major histocompatibility complex; positive selection; rattlesnake; Sistrurus catenatus; trans-species polymorphism

\section{INTRODUCTION}

Proteins of the major histocompatibility complex (MHC) play an important role in the vertebrate immune system by binding and presenting antigens to T-cells (Klein 1986). In most taxa, class I proteins are found on all nucleated cells and bind endogenous peptides, whereas class II proteins are expressed by antigen-presenting cells and bind exogenous peptides (but see Star et al. 2011 for a notable exception). The extraordinary polymorphism exhibited by MHC genes is thought to be maintained by balancing selection (i.e., heterozygote advantage, negative frequency-dependent selection) mediated by host-pathogen interactions (Bernatchez and Landry 2003, Ejsmond et al. 2010, Spurgin and Richardson 2010). In MHC class II, much of this variation is found within the antigen-binding sites (ABS) of the $\beta$ - 1 domain, encoded by exon 2 (Klein 1986).

Genetic diversity at the MHC has been associated with various measures of phenotypic fitness. Low MHC diversity has been linked to increased parasitism and disease susceptibility in birds (Briles et al. 1977), fish (Grimholt et al. 2003), amphibians (Savage and Zamudio 2011), and mammals (Lane et al. 2012). Additionally, MHC variation has been linked to reproductive success in many taxa (Penn 2002, Huchard et al. 2010, Strandh et al. 2012). However, the influence of MHC variation on population viability remains unclear (Radwan et al. 2010).

While recent work has characterized MHC genes in a few non-avian reptiles (Miller et al. 2005, Li et al. 2008, Glaberman et al. 2009), snakes have received less attention (Wittzell et al. 1999, Kelley et al. 2005). What little is known about MHC variation in snakes is largely based on analyses of restriction-fragment length polymorphism (RFLP). Parasite load and longevity are associated with MHC variation in the Water Python (Liasis fuscus; Madsen and Ujvari 2006). Similarly, MHC variation was linked to population viability in the European Adder (Vipera berus; Madsen et al. 1999).

A more complete understanding of $\mathrm{MHC}$ variation in snakes would facilitate investigations into a variety of questions related to the ecology and evolution of snakes. Snakes often rely on olfactory cues for critical behaviors; such as finding mates, locating prey, and avoiding predators (Shine et al. 2005). In addition, an emerging 
fungal disease (Ophidiomyces, formerly Chrysosporium) has been documented in an increasing number of snake populations throughout the eastern United States (Allender et al. 2011). As a potentially relevant parallel, MHC heterozygosity was linked to reduced mortality in amphibians experimentally infected with Batrachochytrium dendrobatidis ( $B d$; Savage and Zamudio 2011). Although the causes and consequences of Ophidiomyces remain unclear, future conservation efforts may benefit from a better understanding of MHC variation in snakes.

The Eastern Massasauga (Sistrurus catenatus) is a small rattlesnake native to the midwestern United States and southern Canada (Figure 1). It is listed as threatened or endangered throughout most of its range and is a candidate for listing under the U.S. Endangered Species Act (USFWS 2010). Historically, the Eastern Massasauga was abundant, but habitat loss and human persecution have contributed to its range-wide decline (Szymanski 1998). Here, we isolate and describe MHC IIB exon 2 sequences in the Eastern Massasauga. These results provide an initial characterization of MHC genes in snakes and contribute to our understanding of MHC evolution. This information will aid in the development of more effective management practices for the Eastern Massasauga, as well as other snakes of conservation concern (Reading et al. 2010).

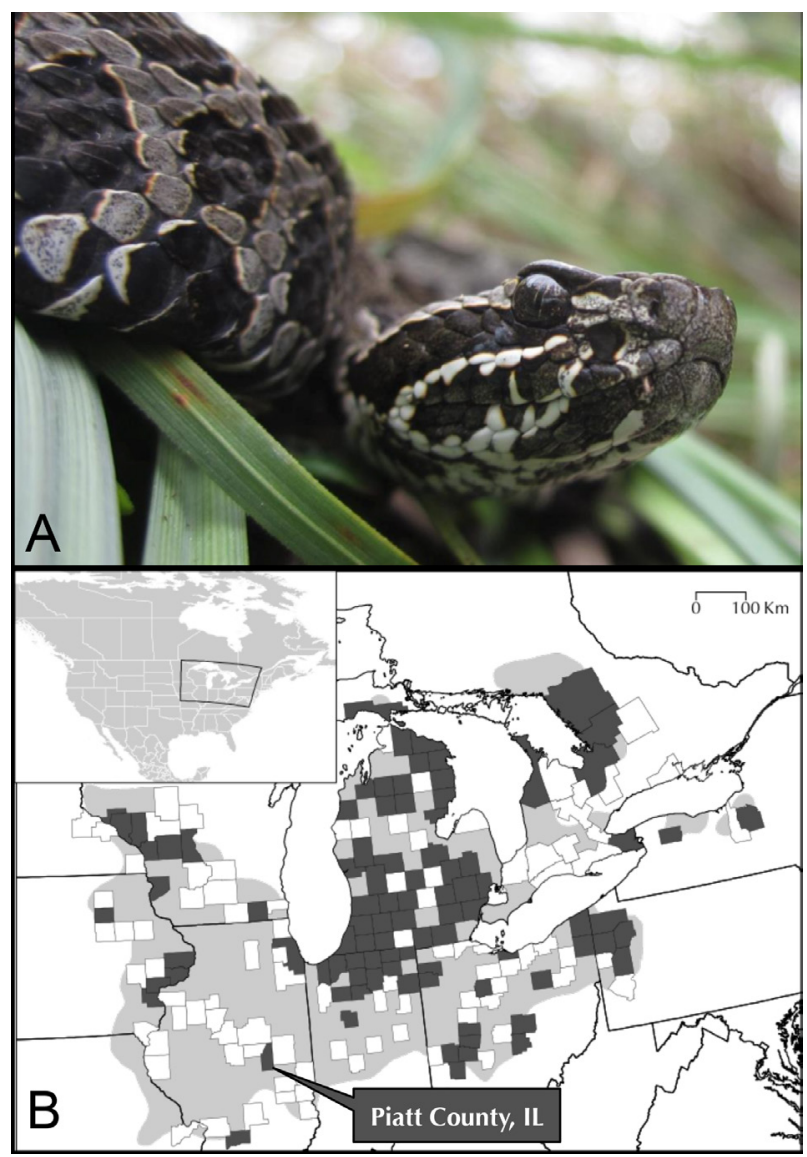

Figure 1. (A) An Eastern Massasauga at a study site in Cass County, Michigan (photo by E. Hileman in 2012). (B) The historical distribution of the Eastern Massasauga is shown in light grey. Dark grey counties contain extant populations. White counties contain extirpated populations.

\section{Molecular methods}

\section{METHODS}

Blood was sampled from three wild-caught Eastern Massasaugas from Piatt County, IL $\left(40^{\circ} 00^{\prime} \mathrm{N}, 88^{\circ} 39^{\prime} \mathrm{W}\right.$; Figure 1). All tissue samples were collected under University of Illinois Urbana-Champaign IACUC protocols \#99283, 02010, 04311, 08019, 10238, 13007, 14000 and Illinois Department of Natural Resources permit $\# 05-11$ S. The samples were stored in $95 \%$ ethanol at $-20{ }^{\circ} \mathrm{C}$ until DNA extraction. Genomic DNA was extracted using Qiagen DNeasy Blood and Tissue Kits (Qiagen, Inc., Valencia, CA) according to the manufacturer's protocols. The degenerate primers MHC-UP (5'-AAG GBC SAG TGY TAC TWY ABB AAC GG-3') and MHC-DP (5'-TAG TTG TGS CKG CAG WAS GTG TC-3') were used to amplify a 166-bp fragment (excluding primers) of MHC IIB exon 2. These primers target conserved regions of exon 2 and have successfully amplified this same fragment in other reptile species (Li et al. 2008).

Amplifications were performed in $30-\mu \mathrm{L}$ reactions containing $1 \times$ GoTaq Flexi Buffer (Promega, Madison, WI, USA), $1 \mathrm{U}$ of GoTaq DNA Polymerase, $200 \mu \mathrm{M}$ of each dNTP, $1.5 \mathrm{mM}$ of magnesium chloride $\left(\mathrm{MgCl}_{2}\right), 0.5 \mu \mathrm{M}$ of each primer, and 50-100 ng of genomic DNA. Cycling conditions were as follows: initial denaturation at $94^{\circ} \mathrm{C}$ for $5 \mathrm{~min}$, followed by $35 \mathrm{cycles}$ of $94^{\circ} \mathrm{C}$ for $30 \mathrm{~s}, 50^{\circ} \mathrm{C}$ for $30 \mathrm{~s}$, and $72{ }^{\circ} \mathrm{C}$ for $30 \mathrm{~s}$, and a final extension at $72^{\circ} \mathrm{C}$ for $5 \mathrm{~min}$. Amplicons were electrophoresed on a $1 \%$ agarose gel stained with ethidium bromide, visualized under ultraviolet light, and photographed with a digital image system (Eastman Kodak, Rochester, NY, USA). A single band of the expected size ( $\sim 215 \mathrm{bp}$ ) was observed.

Amplicons were purified using ExOSAP-IT (USB Corp., Cleveland, $\mathrm{OH}, \mathrm{USA}$ ) and cloned into a TA cloning vector (pGEM-T Easy Vector kit, Promega, Madison, WI, USA). For each snake, a minimum of 32 recombinant colonies were identified using blue-white screening and re-amplified using universal primers MF (5'-TGT AAA ACG ACG GCC AGT-3') and MR2 (5'-TाT CAC ACA GGA AAC AGC$\left.3^{\prime}\right)$. These amplicons were purified (as above) and sequenced through a commercial service (Macrogen, Inc., Seoul, South Korea) using the T7-promoter universal primer (5'-TAA TAC GAC TCA CTA TAG GG-3').

Sequences were inspected and trimmed using Geneious Pro v4.0.2 (Drummond et al. 2012). To avoid the inclusion of PCR/cloning errors, analyses were limited to those MHC sequences that were (1) observed in two or more snakes or (2) observed in two or more independent $\mathrm{PCR} /$ cloning reactions from the same snake (Babik et al. 2005, Kloch et al. 2010).

\section{Data analysis}

CLUSTAL W (Thompson et al. 1994) was used to align confirmed Eastern Massasauga variants. Pairwise uncorrected amino acid $p$-distances and Tamura-Nei genetic distances were calculated using MEGA v5 (Tamura et al. 2011). Nucleotide diversity ( $\Pi$ ) was calculated using the nuc.div function as implemented in the pegas package (Paradis 2010) in R v2.15.2 (R Core Team 2013).

Two approaches were used to test for positive selection. First, the relative rate of non-synonymous to synonymous substitutions $\left(d_{\mathrm{N}} / d_{\mathrm{S}}\right)$ was analyzed separately for the putative antigen-binding sites (ABS; Brown et al. 1993) and nonantigen-binding sites (non-ABS) in MEGA v5 (Tamura et al. 2011) using the modified Nei-Gojobori method (Nei and Kumar 2000) with Jukes-Cantor correction. For each analysis, standard errors were obtained 
Table 1. Summary of MHC IIB exon 2 variants identified via cloning in three individual Eastern Massasaugas. Values indicate the number of colonies containing each variant.

\begin{tabular}{|c|c|c|c|}
\hline & PS04 & $\begin{array}{c}\text { Individual } \\
\text { PS33 }\end{array}$ & PS34 \\
\hline Sica-DAB*01 & 1 & 9 & 7 \\
\hline Sica-DAB*02 & & 5 & 12 \\
\hline Sica-DAB*03 & 1 & 4 & 3 \\
\hline Sica-DAB*04 & 3 & 1 & 6 \\
\hline Sica-DAB*05 & & 2 & 1 \\
\hline Sica-DAB*06 & 2 & 1 & 4 \\
\hline Sica-DAB*07 & $15^{\mathrm{a}}$ & & \\
\hline Sica-DAB*08 & 1 & & 5 \\
\hline Sica-DAB*09b & 2 & & 1 \\
\hline No. Colonies ${ }^{c}$ & $42(25)$ & $32(22)$ & 57 (39) \\
\hline No. Confirmed Variants & 7 & 6 & 8 \\
\hline
\end{tabular}

a Verification based on two independent PCR/cloning reactions for the same individual.

b Putative pseudogene.

c Total number of colonies screened. Number of colonies containing a confirmed variant in parentheses.

based on 1,000 replicates and rates were compared using a Z-test with a significance level of $a=0.05$ (Nei and Kumar 2000). Second, evolutionary models of $d_{N} / d_{\mathrm{S}}$ were analyzed in a maximum likelihood framework using $\mathrm{CO}$ DEML (included in PAML v4.7; Yang 2007). Positively selected sites were identified by comparing nested models of $d_{N} / d_{s}$ : (1) models M1a vs. M2a, (2) models M7 vs. M8. Nested models were compared using likelihood ratio $(L R)$ tests: $L R=2\left[\ln \left(L_{i}\right)-\ln \left(L_{i}\right)\right]$. Results of the $L R$ tests were compared to a $X^{2}$ distribution with a significance level of $a=0.05$ and degrees of freedom equal to the difference in the number of parameters between the models. Positively selected sites were identified using Bayes Empirical Bayes analysis.

The Eastern Massasauga variants were aligned with reptilian MHC IIB exon 2 sequences available on GenBank: Great Snipe (Gallinago media; AY620021), Common Yellowthroat (Geothlypis trichas; GQ247604), Chicken (Gallus gallus; AF09914), Nile Crocodile (Crocodylus niloticus; FJ886741), Spectacled Caiman (Caiman crocodilus; AF256651), Chinese Alligator (Alligator sinensis; AY491421-AY491430), Painted Turtle (Chrysemys picta; AHGY01372457, AHGY01378671, AHGY01394149, AHGY01423642, AHGY01439834, AHGY01507622), Chinese Pond Turtle (Mauremys reevesii; AY937200AY937206), Tuatara (Sphenodon punctatus; DQ124236, DQ124238), Marine Iguana (Amblyrhynchus cristatus; FJ623746-FJ623752), Chinese Skink (Plestiodon chinen-

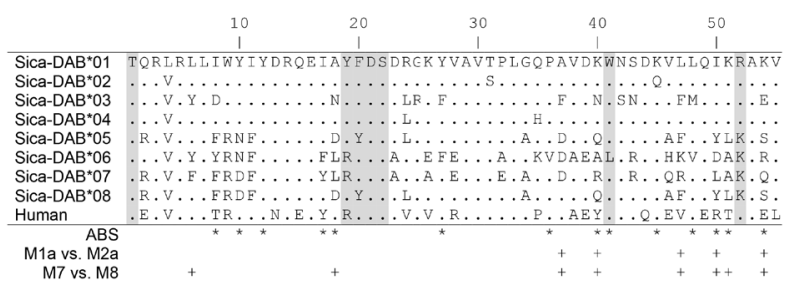

Figure 2. Alignment of MHC IIB exon 2 amino acid sequences of the Eastern Massasauga with a published human sequence (ABB05231). Dots (.) indicate identity with the first sequence. Shading indicates residues expected in functional MHC IIB molecules. Asterisks $\left({ }^{*}\right)$ indicate putative antigen-binding sites (ABS) identified based on homology to the human sequence (Brown et al. 1993). Plus signs (+) indicate sites under positive selection. sis; AY764032, AY772946-AY772951), Krait (Bungarus multicinctus; H0056457), Coral Snake (Micrurus corallinus; FL589895, FL590235). Several sequences not available on GenBank were also included: Grass Snake (Natrix natrix) and Dice Snake (Natrix tessellata; Marosi et al. 2011).

A gene tree was constructed in a Bayesian framework using MrBayes v3 (Ronquist and Huelsenbeck 2003) with a GTR+G+I substitution model selected by jModelTest (Posada 2008). The Chicken sequence (Gallus gallus; AF09914) was specified as the outgroup. Two runs were performed, each with four chains of two million generations, sampling every 100 generations. Trees and parameters were estimated after discarding the first $25 \%$ of samples as burn-in. Analyses were run on the Cyberinfrastructure for Phylogenetic Research (CIPRES v3) cluster at the San Diego supercomputer center (Miller et al. 2010).

\section{RESULTS}

We observed a total of 46 unique MHC IIB exon 2 variants in three individual Eastern Massasaugas. Of these, only nine variants met the "two-PCR" criterion (Babik et al. 2005, Kloch et al. 2010) and were confirmed. These sequences have been deposited in the European Nucleotide Archive (ENA), with accession numbers HG313835HG313843. The remaining 37 variants shared high sequence similarity to the confirmed variants (data not shown), but were only observed in a single individual. Consequently, these sequences were considered PCR/ cloning artifacts and were excluded from subsequent analyses. Eight of the confirmed variants (166 bp excluding primers) were putatively functional and were named Sica-DAB*01-*08 according to nomenclatural standards (Klein et al. 1990). These variants (Sica-DAB*01-*08) share high identity with $\mathrm{MHC}$ sequences from other species, contain open reading frames, and lack frame-shift mutations and premature stop codons (Figure 2). Two Eastern Massasaugas possessed six and one possessed seven of these variants, indicating the presence of at least four MHC IIB loci in this species (Table 1). Four variants (Sica-DAB*01,*03,*04, and *06) were observed in each of the three individuals. The ninth confirmed variant (Sica-DAB*09) contained a 29-bp insertion resulting in a premature stop codon and frame-shift. Although Sica-DAB*09 was observed in two individuals, it may represent a pseudogene. Consequently, Sica-DAB*09 was excluded from subsequent analyses.

Eastern Massasauga MHC IIB exon 2 variants were highly variable. Seventy of $166(42.2 \%)$ nucleotide and 37 of $55(67.3 \%)$ amino acid positions were variable. Nucleotide diversity ( $п$ ) was 0.1833 . Pairwise genetic distances ranged from 1.2 to $51.2 \%$ (overall mean $\pm \mathrm{SE}$ $=26.9 \pm 4.1 \%$ ) and from 3.6 to $54.5 \%$ (overall mean $\pm \mathrm{SE}=34.5 \pm 3.9 \%$ ) for nucleotides and amino acids, respectively (Table 2 ).

We observed evidence of positive selection acting on the Eastern Massasauga MHC Class IIB exon 2 variants $\left(d_{\mathrm{N}} / d_{\mathrm{S}}=2.46, P=0.0004\right.$; Table 3$)$. As expected, selection was strongest on antigen-binding sites (ABS; $d_{N} / d_{S}$ $=4.11, P=0.0008$ ), but significant selection was also observed in other portions of the sequence (non-ABS; $\left.d_{\mathrm{N}} / d_{\mathrm{S}}=1.95, P=0.0173\right)$. Similarly, maximum likelihood analyses indicated positive selection: M1a vs. M2a ( $L R=$ $19.85, d f=2, P<0.0001)$; $M 7$ vs. $M 8(L R=22.86, d f$ $=2, P<0.0001)$. Bayes Empirical Bayes (BEB) analysis identified five positively selected sites when comparing 
Table 2. Pairwise uncorrected amino acid p-distances (above diagonal) and Tamura-Nei genetic distances (below diagonal) among Eastern Massasauga MHC IIB exon 2 variants.

\begin{tabular}{lrrrrrrrr}
\hline & $* 01$ & $* 02$ & $* 03$ & $* 04$ & $* 05$ & $* 06$ & $* 07$ & $* 08$ \\
\hline \hline Sica-DAB*01 & - & 0.055 & 0.255 & 0.055 & 0.327 & 0.527 & 0.436 & 0.309 \\
Sica-DAB*02 & 0.038 & - & 0.273 & 0.073 & 0.345 & 0.545 & 0.455 & 0.327 \\
Sica-DAB*03 & 0.165 & 0.183 & - & 0.236 & 0.382 & 0.527 & 0.509 & 0.382 \\
Sica-DAB*04 & 0.032 & 0.059 & 0.156 & - & 0.309 & 0.527 & 0.455 & 0.291 \\
Sica-DAB*05 & 0.180 & 0.200 & 0.250 & 0.171 & - & 0.491 & 0.327 & 0.036 \\
Sica-DAB*06 & 0.464 & 0.498 & 0.447 & 0.479 & 0.398 & - & 0.364 & 0.527 \\
Sica-DAB*07 & 0.389 & 0.390 & 0.512 & 0.402 & 0.330 & 0.252 & - & 0.327 \\
Sica-DAB*08 & 0.171 & 0.190 & 0.250 & 0.162 & 0.012 & 0.424 & 0.331 & - \\
\hline
\end{tabular}

model M1a vs. model M2a (A37, K40, L47, I50, K54). In addition to these five sites, $B E B$ analysis identified three more positively selected sites ( $66, \mathrm{~A} 18, \mathrm{~K} 51)$ when comparing model M7 vs. M8.

Phylogenetic analysis of reptilian MHC IIB exon 2 sequences resulted in a gene tree (Figure 3 ) in which non-avian reptilian sequences formed a well-supported clade, and there was strong support for a clade containing snake MHC sequences. Within this snake clade, the MHC gene tree differed topologically from species-level phylogenetic relationships, suggesting a pattern of trans-species polymorphism. However, several of these nodes received low support (posterior probability < 0.90).

\section{DISCUSSION}

We have provided evidence of at least four MHC IIB loci in the Eastern Massasauga (Sistrurus catenatus). We identified eight putatively functional MHC IIB exon 2 variants (Sica-DAB*01-*08), and we found one putative pseudogene (Sica-DAB*09). Pseudogenes have

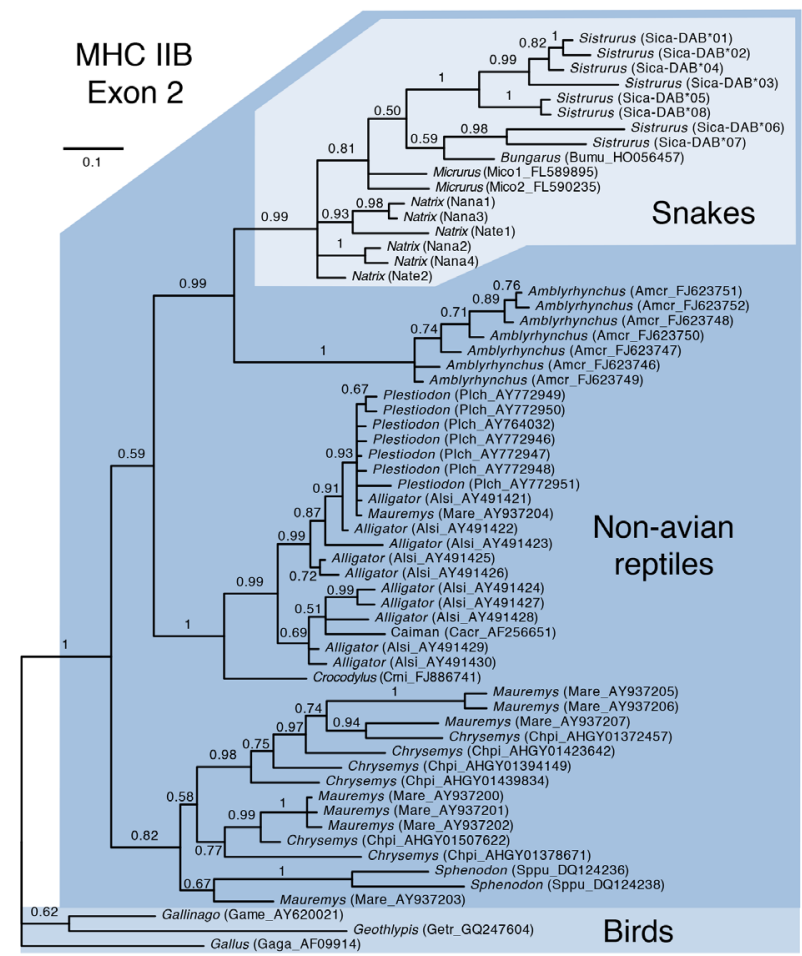

Figure 3. Bayesian gene tree of reptilian MHC IIB exon 2 sequences. Branch lengths are proportional to the number of substitutions per site. Bayesian posterior probability values are indicated for each node. been reported in other taxa, including birds (Hess et al. 2000, Aguilar et al. 2005) and mammals (Hughes 1995, Wilming et al. 2013). More extensive sampling using next-generation sequencing methods is ongoing (Jaeger et al., unpublished) which may clarify this result.

Although more than 30 clones were sequenced for each of the three snakes, $37 \mathrm{MHC}$ variants could not be confirmed. This may indicate the presence of additional loci and/or high rate of PCR/cloning error (Lenz and Becker 2008). A cDNA sequence analysis is needed to assess the degree to which these loci are expressed. Such an analysis would also permit the development of locusspecific primers (Glaberman et al. 2009).

The number of MHC loci is also known to vary within and among species (Siddle et al. 2010, Cheng et al. 2012). Two variants were identified in the Dice Snake and four variants were observed in one individual Grass Snake (Marosi et al. 2011), but too few clones were examined to reliably infer the number of loci. Four loci were identified in the Marine Iguana (Glaberman et al. 2009) and the Tuatara (Miller et al. 2005). Massively parallel 454 amplicon sequencing revealed at least nine putatively expressed MHC IIB loci in the Collared Flycatcher (Ficedula albicollis; Zagalska-Neubauer et al. 2010).

The Eastern Massasauga MHC IIB sequences contained an RFDS motif and a tyrosine residue which are thought to play important roles in T-cell interactions and hydrogen bonding with the antigen, respectively (Mazerolles et al. 1988). In addition, MHC IIB proteins typically contain a NGT glycosylation site within the $\beta-1$ domain. This motif has been observed in MHC IIB sequences of nearly all vertebrate taxa examined to date, with the notable exception of the Marine Iguana (Glaberman et al. 2009). Indeed, the forward primer used in this study was designed to target this conserved portion of the gene. While our methods cannot provide direct evidence, successful amplification suggests that the NGT glycosylation site is present in the Eastern Massasauga MHC.

The confirmed Eastern Massasauga MHC IIB variants exhibited relatively high nucleotide $(26.9 \pm 4.1 \%)$ and amino acid (34.5 $\pm 3.9 \%)$ distances. These values are higher than similar metrics in the Marine Iguana (Glaberman et al. 2009) and the Tuatara (Miller et al. 2005). Nucleotide diversity in the Eastern Massasauga $(n=0.183$ ) is also higher than that in the Marine Iguana ( $n=0.065$; Glaberman et al. 2009), the Chinese Alligator $(n=0$. 092; Li et al. 2008) and the Chinese Skink ( $\Pi=0.022)$, but comparable to that in the Chinese Pond Turtle $(n=$ 0.222 ).

The portion of exon 2 examined in this study includes 14 amino acid residues corresponding to the antigen-binding sites (ABS) in humans, as identified from the crystal structure (Brown et al. 1993). We observed relatively higher rates of nonsynonymous to synonymous substitu- 
Table 3. Evidence of positive selection on MHC IIB exon 2 variants in the Eastern Massasauga. The relative rates ( $d_{N} / d_{S}$ ) of nonsynonymous $\left(d_{N}\right)$ to synonymous $\left(d_{s}\right)$ substitutions were compared for the entire sequence, and separately for the putative antigen-binding sites (ABS) and other sites.

\begin{tabular}{lcccr}
\hline & $\mathrm{d}_{\mathrm{N}}$ & $\mathrm{d}_{\mathrm{S}}$ & $\mathrm{d}_{\mathrm{N}} / \mathrm{d}_{\mathrm{s}}$ & $\mathrm{P}$ Z-value \\
\hline \hline Entire & $0.274 \pm 0.049$ & $0.111 \pm 0.028$ & 2.46 & 3.45 \\
ABS & $0.638 \pm 0.172$ & $0.155 \pm 0.082$ & 4.11 & 3.22 \\
Other & $0.192 \pm 0.040$ & $0.098 \pm 0.031$ & 1.95 & 0.0008 \\
\hline
\end{tabular}

tions $\left(d_{N} / d_{\mathrm{s}}\right)$ when examining the entire sequences, and $d_{\mathrm{N}} / d_{\mathrm{S}}$ was highest in the ABS, as expected. Five of the eight positively selected sites identified corresponded to $A B S$ residues. The remaining nine $A B S$ residues did not appear to be under positive selection. This suggests that the structure of the antigen-binding cleft in the Eastern Massasauga MHC IIB protein may differ from that of mammals. An alternative explanation is that not all of the ABS residues are under strong positive selection. Similar results have been reported in fish (Hedrick et al. 2001), lizards, turtles, and crocodilians (Li et al. 2008). Analysis of the three-dimensional structure of the Eastern Massasauga MHC IIB protein is needed to address this question.

Phylogenetic analysis indicated strong support for a clade containing non-avian reptile MHC sequences; however, snake sequences do not cluster according to species-level phylogenetic relationships (Pyron et al. 2011, 2013). This may suggest a pattern of trans-species polymorphism (Klein 1987), which provides further evidence that these genes are under selection (Mayer et al. 1992, Garrigan and Hedrick 2003, Ottova et al. 2005, Edwards 2009, Strandh et al. 2012). More thorough taxonomic sampling and the analysis of longer sequences would likely improve the resolution of this tree and provide a more complete view of $\mathrm{MHC}$ evolution in non-avian reptiles.

Theoretical and experimental data suggest that the extraordinarily high variation of MHC genes is maintained via some form of pathogen-mediated selection, such as heterozygote advantage or negative frequency-dependent selection (Spurgin and Richardson 2010). While strong selection has been shown to maintain MHC diversity in some small, isolated populations (Aguilar et al. 2004), genetic drift may overpower selection and can result in a loss of adaptive genetic variation (Sutton et al. 2011). Our results are of particular importance in light of global reptile declines (Reading et al. 2010). Moreover, recent work has identified emerging fungal (Allender et al. 2011, 2013) and viral (Hyndman et al. 2012) pathogens in snakes. Information related to adaptive variation at functional loci, such as the MHC, can provide insight into an individual's susceptibility to these pathogens (Hedrick 2002) and, when used in combination with selectively neutral DNA markers, can inform conservation efforts in the field and in captivity (Radwan et al. 2010). More generally, ectothermic vertebrates (including snakes) play an important role in the transmission cycle of some pathogens (Bingham et al. 2012). A more complete understanding of the interactions between snakes and their pathogens will contribute to more effective management of wildlife diseases (Joseph et al. 2013).

In summary, genetic variation within and among the Eastern Massasauga has been examined using selectively neutral loci (Gibbs et al. 1997, Gibbs and Chiucchi 2012, Ray et al. 2013, DiLeo et al. 2013). By characterizing MHC IIB variation, we hope to complement previous efforts and offer an initial view of adaptive genetic vari- ation in this endangered rattlesnake. We are currently implementing next-generation 454 pyrosequencing to obtain MHC genotypes for Eastern Massasauga samples collected from multiple populations of varying sizes and demographic histories. Levels of adaptive variation (i.e., $\mathrm{MHC}$ ) will be compared to those of selectively neutral loci (i.e., microsatellites) to examine the relative roles of selection and drift in shaping genetic variation within this species. This information will contribute to the management of wild and captive Eastern Massasauga populations as part of the Association of Zoos and Aquariums Species Survival Plan (SSP; Earnhardt et al. 2011, Ray et al. 2013).

\section{ACKNOWLEDGEMENTS}

We thank Renee Kopulos for valuable MHC discussions and Andrew Iverson for technical assistance. We are grateful to Michael Dreslik, Chris Phillips, and John Griesbaum at the Illinois Natural History Survey for providing tissue samples. This work was funded by the Department of Biological Sciences at Northern Illinois University. We gratefully acknowledge input provided by two anonymous reviewers and the editor to improve the manuscript.

\section{LITERATURE CITED}

Aguilar, A., G. Roemer, S. Debenham, M. Binns, D. Garcelon, and R. K. Wayne. 2004. High MHC diversity maintained by balancing selection in an otherwise genetically monomorphic mammal. Proceedings of the National Academy of Sciences, USA 101:34903494.

Aguilar, A., T. Smith, and R. K. Wayne. 2005. A comparison of variation between a MHC pseudogene and microsatellite loci of the little greenbul (Andropadus virens). BMC Evolutionary Biology 5:47.

Allender, M. C., M. Dreslik, S. Wylie, C. Phillips, D. Wylie, M. C, M. A. Delaney, and M. J. Kinsel. 2011. Chrysosporium sp. infection in eastern massasauga rattlesnakes. Emerging Infectious Diseases 17:2383-2384.

Allender, M. C., M. J. Dreslik, D. B. Wylie, S. J. Wylie, J. W. Scott, and C. A. Phillips. 2013. Ongoing health assessment and prevalence of Chrysosporium in the eastern massasauga (Sistrurus catenatus catenatus). Copeia 2013:97-102.

Babik, W., W. Durka, and J. Radwan. 2005. Sequence diversity of the MHC DRB gene in the Eurasian beaver (Castor fiber). Molecular Ecology 14:4249-4257.

Bernatchez, L., and C. Landry. 2003. MHC studies in nonmodel vertebrates: what have we learned about natural selection in 15 years? Journal of Evolutionary Biology 16:363-377.

Bingham, A. M., S. P. Graham, N. D. Burkett-Cadena, G. S. White, H. K. Hassan, and T. R. Unnasch. 2012. Detection of eastern equine encephalomyelitis virus RNA in North American snakes. American Journal of Tropical Medicine and Hygiene 87:1140-1144.

Briles, W. E., H. A. Stone, and R. K. Cole. 1977. Marek's 
disease: effects of B histocompatibility alloalleles in resistant and susceptible chicken lines. Science 195: 193-195.

Brown, J. H., T. S. Jardetzky, J. C. Gorga, L. J. Stern, R. G. Urban, J. L. Strominger, and D. C. Wiley. 1993. Three-dimensional structure of the human class II histocompatibility antigen HLA-DR1. Nature 364:33-39.

Cheng, Y., A. Stuart, K. Morris, R. Taylor, H. Siddle, J. Deakin, M. Jones, C. T. Amemiya, and K. Belov. 2012. Antigen-presenting genes and genomic copy number variations in the Tasmanian devil MHC. BMC Genomics 13:87.

DiLeo, M. F., J. D. Rouse, J. A. Dávila, and S. C. Lougheed. 2013. The influence of landscape on gene flow in the eastern massasauga rattlesnake (Sistrurus c. catenatus): insight from computer simulations. Molecular Ecology 22:In Press.

Drummond, A., B. Ashton, S. Buxton, M. Cheung, A. Cooper, C. Duran, M. Field, J. Heled, M. Kearse, S. Markowitz, R. Moir, S. Stones-Havas, S. Sturrock, T. Thierer, and A. Wilson. 2012. Geneious Pro v4. Available from http://www.geneious.com.

Earnhardt, J., D. Mulkerin, and S. Long. 2011. Population analysis and breeding and transfer plan: eastern massasauga rattlesnake (Sistrurus catenatus catenatus) AZA species survival plan program. Chicago: Lincoln Park Zoo. Available: http://www.emrssp. org/asets/files/2011_executive_summary.doc.

Edwards, S. V. 2009. Natural selection and phylogenetic analysis. Proceedings of the National Academy of Sciences, USA 106:8799-8800.

Ejsmond, M., W. Babik, and J. Radwan. 2010. MHC allele frequency distributions under parasite-driven selection: A simulation model. BMC Evolutionary Biology $10: 332$.

Garrigan, D., and P. W. Hedrick. 2003. Detecting adaptive molecular polymorphism: Lessons from the MHC. Evolution 57:1707-1722.

Gibbs, H. L., and J. E. Chiucchi. 2012. Inbreeding, body condition, and heterozygosity-fitness correlations in isolated populations of the endangered eastern massasauga rattlesnake (Sistrurus c. catenatus). Conservation Genetics 13:1133-1143.

Gibbs, H. L., K. A. Prior, P. J. Weatherhead, and G. Johnson. 1997. Genetic structure of populations of the threatened eastern massasauga, Sistrurus c. catenatus: evidence from microsatellite DNA markers. Molecular Ecology 6:1123-1132.

Glaberman, S., M. A. Moreno, and A. Caccone. 2009. Characterization and evolution of MHC class II B genes in Galápagos marine iguanas (Amblyrhynchus cristatus). Developmental and Comparative Immunology 33:939-947.

Grimholt, U., S. Larsen, R. Nordmo, P. Midtlyng, S. Kjoeglum, A. Storset, S. Saebø, and R. J. M. Stet. 2003. MHC polymorphism and disease resistance in Atlantic salmon (Salmo salar); facing pathogens with single expressed major histocomptability class I and class II loci. Immunogenetics 55:210-219.

Hedrick, P. W. 2002. Pathogen resistance and genetic variation at MHC loci. Evolution 56:1902-1908.

Hedrick, P. W., K. M. Parker, and R. N. Lee. 2001. Using microsatellite and $\mathrm{MHC}$ variation to identify species, ESUs, and MUs in the endangered Sonoran topminnow. Molecular Ecology 10:1399-1412.

Hess, C., J. Gasper, H. Hoekstra, C. Hill, and S. V. Ed- wards. 2000. MHC class II pseudogene and genomic signature of a 32-kb cosmid in the house finch (Carpodacus mexicanus). Genome Research 10:613623.

Huchard, E., L. A. Knapp, J. Wang, M. Raymond, and G. Cowlishaw. 2010. MHC, mate choice and heterozygote advantage in a wild social primate. Molecular Ecology 19:2545-2561.

Hughes, A. L. 1995. Origin and evolution of HLA class I pseudogenes. Molecular Biology and Evolution $12: 247-258$

Hyndman, T. H., C. M. Shilton, R. J. T. Doneley, and P. K. Nicholls. 2012. Sunshine virus in Australian pythons. Veterinary Microbiology 161:77-87.

Joseph, M. B., J. R. Mihaljevic, A. L. Arellano, J. G. Kueneman, D. L. Preston, P. C. Cross, and P. T. J. Johnson. 2013. Taming wildlife disease: bridging the gap between science and management. Journal of Applied Ecology 50:702-712.

Kelley, J., L. Walter, and J. Trowsdale. 2005. Comparative genomics of major histocompatibility complexes. Immunogenetics 56:683-695.

Klein, J. 1986. Natural history of the major histocompatibility complex. New York: John Wiley \& Sons.

Klein, J. 1987. Origin of major histocompatibility complex polymorphism: The trans-species hypothesis. Human Immunology 19:155-162.

Klein, J., R. E. Bontrop, R. L. Dawkins, H. A. Erlich, U. B. Gyllensten, E. R. Heise, P. P. Jones, P. Parham, E. K. Wakeland, and D. I. Watkins. 1990. Nomenclature for the major histocompatibility complexes of different species: a proposal. Immunogenetics 31:217-219.

Kloch, A., W. Babik, A. Bajer, E. Sinski, and J. Radwan. 2010. Effects of an MHC-DRB genotype and allele number on the load of gut parasites in the bank vole Myodes glareolus. Molecular Ecology 19:255-265.

Lane, A., Y. Cheng, B. Wright, R. Hamede, L. Levan, M. Jones, B. Ujvari, and K. Belov. 2012. New insights into the role of MHC diversity in devil facial tumour disease. PLoS ONE 7:e36955.

Lenz, T. L., and S. Becker. 2008. Simple approach to reduce PCR artefact formation leads to reliable genotyping of $\mathrm{MHC}$ and other highly polymorphic loci - Implications for evolutionary analysis. Gene 427:117-123.

Li, E., X. B. Wu, and P. Yan. 2008. Genetic variation and trans-species polymorphism of MHC class II B genes in reptiles. Asiatic Herpetological Research 11:5056.

Madsen, T., and B. Ujvari. 2006. MHC class I variation associates with parasite resistance and longevity in tropical pythons. Journal of Evolutionary Biology 19:1973-1978.

Madsen, T., R. Shine, M. Olsson, and H. Wittzell. 1999. Restoration of an inbred adder population. Nature 402:34-35.

Marosi, B., I. Ghira, T. Sos, and O. Popescu. 2011. Identification of partial MHC class II B exon 2 sequences in two closely related snake species: Natrix tessellata and Natrix natrix. Herpetologica Romanica 5:1-6.

Mayer, W., C. O'huigin, Z. Zaleska-Rutczynska, and J. Klein. 1992. Trans-species origin of Mhc-DRB polymorphism in the chimpanzee. Immunogenetics 37:12-23.

Mazerolles, F., A. Durandy, D. Piatier-Tonneau, D. Charron, L. Montagnier, C. Auffray, and A. Fischer. 1988. 
Immunosuppressive properties of synthetic peptides derived from CD4 and HLA-DR antigens. Cell 55:497-504.

Miller, H. C., K. Belov, and C. H. Daugherty. 2005. Characterization of MHC class II genes from an ancient reptile lineage, Sphenodon (tuatara). Immunogenetics 57:883-891.

Miller, M. A., W. Pfeiffer, and T. Schwartz. 2010. Creating the CIPRES Science Gateway for inference of large phylogenetic trees. Gateway Computing Environments Workshop (GCE), 2010:1-8.

Nei, M., and S. Kumar. 2000. Molecular Evolution and Phylogenetics. Oxford University Press.

Ottova, E., A. Šimková, J. Martin, and J. Goüy de. 2005. Evolution and trans-species polymorphism of $M H C$ class II $\beta$ genes in cyprinid fish. Fish \& Shellfish Immunology 18:199-222.

Paradis, E. 2010. pegas: an R package for population genetics with an integrated-modular approach 26:419-420.

Penn, D. J. 2002. The scent of genetic compatibility: Sexual selection and the major histocompatibility complex. Ethology 108:1-21.

Posada, D. 2008. jModelTest: phylogenetic model averaging. Molecular Biology and Evolution 25:12531256.

Pyron, R. A., F. T. Burbrink, and G. Colli. 2011. The phylogeny of advanced snakes (Colubroidea), with discovery of a new subfamily and comparison of support methods for likelihood trees. Molecular Phylogenetics and Evolution 58:329-342.

Pyron, R. A., F. T. Burbrink, and J. J. Wiens. 2013. A phylogeny and revised classification of Squamata, including 4161 species of lizards and snakes. BMC Evolutionary Biology 13:93.

R Core Team. 2013. R: a language and environment for statistical computing. R Foundation for Statistical Computing, Vienna, Austria. URL http://www.R-project.org/.

Radwan, J., A. Biedrzycka, and W. Babik. 2010. Does reduced MHC diversity decrease viability of vertebrate populations? Biological Conservation 143:537-544.

Ray, J. W., R. B. King, M. R. Duvall, J. W. Robinson, C. P. Jaeger, M. J. Dreslik, B. J. Swanson, and D. Mulkerin. 2013. Genetic analysis and captive breeding program design for the eastern massasauga Sistrurus catenatus catenatus. Journal of Fish and Wildlife Management 4:104-113.

Reading, C. J., L. M. Luiselli, G. C. Akani, X. Bonnet, G. Amori, J. M. Ballouard, E. Filippi, G. Naulleau, D. Pearson, and L. Rugiero. 2010. Are snake populations in widespread decline? Biology Letters 6:777780.

Ronquist, F., and J. P. Huelsenbeck. 2003. MrBayes 3: Bayesian phylogenetic inference under mixed models. Bioinformatics 19:1572-1574.

Savage, A. E., and K. R. Zamudio. 2011. MHC genotypes associate with resistance to a frog-killing fungus. Proceedings of the National Academy of Sciences, USA 108:16705-16710.

Shine, R., J. K. Webb, A. LANE, and R. T. Mason. 2005. Mate location tactics in garter snakes: effects of rival males, interrupted trails and non-pheromonal cues. Functional Ecology 19:1017-1024.

Siddle, H. V., J. Marzec, Y. Cheng, M. Jones, and K. Belov. 2010. MHC gene copy number variation in Tasmanian devils: implications for the spread of a contagious cancer. Proceedings of the Royal Society of
London. B Biological Sciences 277:2001-2006.

Spurgin, L. G., and D. S. Richardson. 2010. How pathogens drive genetic diversity: $\mathrm{MHC}$, mechanisms and misunderstandings. Proceedings of the Royal Society of London. B Biological Sciences 277:979-988.

Star, B., A. J. Nederbragt, S. Jentoft, U. Grimholt, M. Malmstrøm, T. F. Gregers, T. B. Rounge, J. Paulsen, M. H. Solbakken, A. Sharma, O. F. Wetten, A. Lanzén, R. Winer, J. Knight, J.-H. Vogel, B. Aken, $\varnothing$. Andersen, K. Lagesen, A. Tooming-Klunderud, R. B. Edvardsen, K. G. Tina, M. Espelund, C. Nepal, C. Previti, B. O. Karlsen, T. Moum, M. Skage, P. R. Berg, T. Gjøen, H. Kuhl, J. Thorsen, K. Malde, R. Reinhardt, L. Du, S. D. Johansen, S. Searle, S. Lien, F. Nilsen, I. Jonassen, S. W. Omholt, N. C. Stenseth, and K. S. Jakobsen. 2011. The genome sequence of Atlantic cod reveals a unique immune system. Nature 477:207-210.

Strandh, M., H. Westerdahl, M. Pontarp, B. Canback, M. P. Dubois, C. Miquel, P. Taberlet, and F. Bonadonna. 2012. Major histocompatibility complex class II compatibility, but not class I, predicts mate choice in a bird with highly developed olfaction. Proceedings of the Royal Society of London. B Biological Sciences 279:4457-4463.

Sutton, J. T., S. Nakagawa, B. C. Robertson, and I. G. Jamieson. 2011. Disentangling the roles of natural selection and genetic drift in shaping variation at $\mathrm{MHC}$ immunity genes. Molecular Ecology 20:4408-4420.

Szymanski, J. 1998. Status assessment for eastern massasauga (Sistrurus c. catenatus). U.S. Fish and Wildlife Service, Endangered Species Division, Fort Snelling, MN.

Tamura, K., D. Peterson, N. Peterson, G. Stecher, M. Nei, and S. Kumar. 2011. MEGA5: molecular evolutionary genetics analysis using maximum likelihood, evolutionary distance, and maximum parsimony methods. Molecular Biology and Evolution 28:27312739.

Thompson, J. D., D. G. Higgins, and T. J. Gibson. 1994. CLUSTAL W: improving the sensitivity of progressive multiple sequence alignment through sequence weighting, position-specific gap penalties and weight matrix choice. Nucleic Acids Research 22:4673-4680.

USFWS. 2010. Endangered and threatened wildlife and plants; review of native species that are candidates for listing as endangered or threatened; annual notice of findings on resubmitted petitions; annual descriptions of progress on listing actions. Federal Register 75:69222-69294.

Wilming, L. G., E. A. Hart, P. C. Coggill, R. Horton, J. G. R. Gilbert, C. Clee, M. Jones, C. Lloyd, S. Palmer, S. Sims, S. Whitehead, D. Wiley, S. Beck, and J. L. Harrow. 2013. Sequencing and comparative analysis of the gorilla MHC genomic sequence. Database 2013: bat011-bat011.

Wittzell, H., T. Madsen, H. Westerdahl, R. Shine, and T. von Schantz. 1999. MHC variation in birds and reptiles. Genetica 104:301-309.

Yang, Z. 2007. PAML 4: Phylogenetic Analysis by Maximum Likelihood. Molecular Biology and Evolution 24:1586-1591.

Zagalska-Neubauer, M., W. Babik, M. Stuglik, L. Gustafsson, M. Cichoń, and J. Radwan. 2010. 454 sequencing reveals extreme complexity of the class II Major Histocompatibility Complex in the collared flycatcher. BMC Evolutionary Biology 10:395. 